1 Universidade Estadual do Oeste do Paraná (Unioeste), Programa de Pós-Graduação em Biociências e Saúde Curitiba (PR), Brasil. Centro Estadual de Saúde do Trabalhador (Cest) Curitiba (PR), Brasil. nanferpinto@gmail.com

2 Universidade Estadual do Oeste do Paraná (Unioeste), Programa de Pós-Graduação em Biociências e Saúde Cascavel (PR), Brasil. neidetm@terra.com.br

\section{Processos protetores e destrutivos da saúde dos(as) trabalhadores(as) da sericicultura}

\author{
Protective and destructive processes of the health of the sericulture's \\ workers
}

Nanci Ferreira Pinto', Neide Tiemi Murofuse ${ }^{\mathbf{2}}$

\begin{abstract}
RESUMO Este artigo identifica os processos protetores e destrutivos da saúde dos trabalhadores da sericicultura no Paraná. Trata-se de estudo qualitativo, realizado com grupo de produtores de casulo de seda dos municípios de Arapongas e Diamante do Sul. O modo de vida das famílias se caracteriza por: dificuldade de linhas de produção autônomas; desenvolvimento de várias atividades para compor a renda; contato com substâncias químicas tóxicas; jornadas prolongadas de trabalho; situações de sofrimento. Como processos protetores, a organização dos trabalhadores e o acesso a alguma política pública. É urgente o monitoramento da saúde desses trabalhadores, em especial, referente ao uso do formol.
\end{abstract}

PALAVRAS-CHAVE Saúde do trabalhador. Condições de trabalho. Carga de trabalho. Dominação-subordinação.

ABSTRACT This article identifies the protective and destructive processes of the health of sericulture's workers in Paraná. It is a qualitative study, with a group of silk cocoon producers in the municipalities of Arapongas and Diamante do Sul. The lifestyle of the families is characterized by: difficulty of autonomous production lines; development of many activities to compose income; contact with toxic chemicals; long working hours; situations of suffering. As protective processes, the organization of the workers and the access to some public policy. Monitoring the health of these workers is urgently required, especially, regarding the use of formaldehyde.

KEYWORDS Occupational health. Working conditions. Workload. Domination-subordination. 


\section{Introdução}

As mudanças ocorridas no campo, nas últimas décadas, impuseram alterações profundas ao modo de vida das famílias dos pequenos agricultores, com repercussão no processo saúde-doença. Entre essas mudanças, está a integração da agricultura ao setor industrial, na qual há uma subordinação real dos trabalhadores familiares às empresas capitalistas. Nesta esteira, se coloca a atividade da criação do bicho-da-seda e do cultivo da amoreira, denominada sericicultura.

No Brasil, essa atividade é realizada por pequenos produtores e monopolizada por uma indústria. A produção é voltada principalmente para o mercado externo e envolve em torno de 2,5 mil produtores (BRATAC, 2013).

A sericicultura tem sido tratada como uma atividade sem impacto à saúde das pessoas e ao meio ambiente (BRANCALHÃO; TORQUATO; CASTRO, 2002; TAKAHASHI; TAKAHASHI; TAKAHASHI, 2009). Por outro lado, estudos internacionais, em relação ao quadro saúde-doença dos trabalhadores na sericicultura, encontraram ocorrência de tosse, resfriados e alergias (VIJAYABHASKARARAO ET AL., 2013); irritação nos olhos, feridas, dor nas costas, problemas respiratórios e dores de cabeça (WANI; JAISWAL, 2011). Embora seja uma atividade com potenciais riscos de acidentes e doenças do trabalho, decorrentes da exposição dos sericicultores aos diversos tipos de cargas de trabalho (física, química, mecânica, fisiológica, psíquica), no Brasil, não foram identificadas pesquisas específicas sobre tal temática, indicando a necessidade de estudos para suprimir esta lacuna (PINTO; MUROFUSE; CARVALHO, 2015).

Assim, o ponto de partida desta pesquisa foi um conjunto de fatos aparentes, que, por um lado, indicavam a positividade do trabalho e, por outro, sinalizavam possíveis processos deletérios à saúde dos trabalhadores. Nesta perspectiva, o objetivo do presente estudo é investigar o modo de vida do trabalho dos sericicultores, para identificar os processos protetores e destrutivos da saúde, visando apresentar elementos para a vigilância em saúde do trabalhador.

\section{Material e métodos}

Trata-se de pesquisa documental e de campo, de natureza qualitativa. A pesquisa qualitativa, na interpretação das questões investigadas, trabalha com o universo de significados, motivos, aspirações, crenças, valores e atitudes, o que corresponde a um espaço mais profundo das relações, dos processos e dos fenômenos, que não podem ser reduzidos à operacionalização de variáveis (MINAYO, 2002).

Compreender o processo saúde-doença dos trabalhadores implica investigar como a problemática é gerada. Para tanto, conforme Laurell e Noriega (1989), considera-se elemento metodológico fundamental o conhecimento que os trabalhadores têm sobre o processo de trabalho, pretendendo, assim, desvendá-lo, além de possibilitar práticas sociais de transformação das condições desse trabalho.

Nesse sentido, no presente estudo, as técnicas de coleta utilizadas foram as entrevistas e o grupo focal com produtores de casulo de seda dos municípios de Arapongas (PR) e Diamante do Sul (PR), situados, respectivamente, nas regiões norte e oeste do estado do Paraná. O primeiro município foi escolhido por se tratar de assentamento rural, com um processo organizativo diferenciado em relação aos produtores individuais; e o segundo, por ser considerado o que apresenta a melhor qualidade de produção, desde o ano de 2011.

Os participantes do estudo foram nove sericicultores, sendo seis homens e três mulheres, na faixa etária de 35 a 55 anos, com escolaridades de ensino fundamental a médio. A seleção dos entrevistados cumpriu os seguintes critérios de inclusão e exclusão preestabelecidos: ser trabalhador e/ou ex-trabalhador da sericicultura; adulto com idade acima de 21 anos; ter disponibilidade 
de participar da pesquisa no período estabelecido; concordar com a participação voluntária; e assinar o Termo de Consentimento Livre e Esclarecido.

Para realizar as entrevistas e o grupo focal, foram utilizados dois roteiros, com os seguintes temas: processo e condições de trabalho, condições de vida, acesso às políticas públicas, relação com o meio ambiente, organização política. Os roteiros foram previamente elaborados, e a conversa foi gravada. A pesquisa foi aprovada pelo Comitê de Ética em Pesquisa com Seres Humanos sob o parecer $n^{0} 377.364$, de 29/08/2013.

A técnica da observação participante, além da entrevista semiestruturada e do grupo focal com os sericicultores, foi outra fonte de dados utilizada, e os conteúdos das 12 visitas realizadas nas propriedades rurais foram registrados no diário de campo. Recorreu-se, ainda, a outras fontes: informações obtidas nas conversas com as lideranças do Assentamento Dorcelina Folador, em Arapongas (PR), e com os técnicos de Diamante do Sul (PR), da empresa de fiação de seda, a Bratac, além dos documentos de órgãos públicos de saúde, agricultura, trabalho e ambiente que tratavam do processo produtivo da sericicultura.

As informações coletadas passaram pelo processo de ordenação, classificação e análise. O tratamento dos dados ocorreu a partir da identificação dos elementos correspondentes às instâncias singular, particular e geral. Para a análise dos dados, utilizou-se a perspectiva crítica, fundamentada na proposição de Breilh (2006), o qual entende que o processo saúde-doença dos trabalhadores deve ser abordado como um processo unitário e dinâmico, que configure os modos de vida. Ou seja, compreender a posição que os atores ocupam na estrutura produtiva, os padrões laborais, os sistemas de consumo, condições de vida que dizem respeito à moradia, alimentação, descanso, acesso e qualidade de serviços; e as relações dos grupos com a natureza, as suas concepções, valores e formas organizativas. Também se procurou capturar a dupla faceta do trabalho, benéfico/destrutivo, do grupo laboral escolhido, com base no entendimento de que os processos que ocorrem na sociedade e nos "[...] modos de vida grupais", podem ser protetores quando "[...] se convertem num favorecedor das defesas e suportes e estimulam uma direcionalidade favorável à vida humana" e, por outro lado, quando os processos provocam "[...] privação ou deterioração da vida humana, individual ou coletiva", são chamados de "processos destrutivos" (BREILH, 2006, P. 203). Nesse sentido, com base em Breilh (2010), agruparam-se os dados coletados em quatro tipos de domínio:

a) do processo técnico de produção, que diz respeito à vida produtiva, incluindo o trabalho e o direito dos trabalhadores;

b) aspectos da vida de consumo e cotidianidade, que diz respeito ao acesso a bens e consumo;

c) aspectos da vida política e ideológica, que se expressa na organização dos trabalhadores e em como o indivíduo pensa a sociedade;

d) aspectos da vida de relação com o ambiente, que diz respeito à relação com a natureza.

Realizada a categorização, procedeu-se à articulação entre os dados empíricos e as questões macro e microssociais, considerando-se o aporte da literatura consultada e as conexões com as informações obtidas pela pesquisa documental, o que permitiu a realização de um ensaio da matriz de processos críticos.

\section{Resultados e discussão}

Inicialmente, apresenta-se a caracterização dos participantes da pesquisa, e, na sequência, os resultados obtidos referentes a cada 
um dos quatro domínios. Por fim, os processos protetores, que potencializam a saúde, e os processos destrutivos, que acentuam os quadros de doença e morte dos sericicultores, visando buscar subsídios que permitam a construção da vigilância da saúde dos trabalhadores.

O grupo pesquisado de trabalhadores(as) estava na atividade da sericicultura em períodos que variaram entre 7 e 14 anos. Além disso, tanto para complementar a renda quanto para o consumo da família, trabalhavam com leite, café e hortifrutigranjeiros - mandioca, batata doce, laranja, abacate e banana. Todos os entrevistados indicaram a 'opção' pela atividade de sericicultura devido ao baixo custo de implantação; à compensação financeira; à assistência técnica fornecida pela empresa; à impossibilidade de acompanhar a dinâmica da produção agrícola, que privilegia o plantio de soja, milho, trigo e cana; e à dificuldade de acesso ao financiamento público.

Tais resultados corroboram as afirmações de Ojeda (2012), que afirma tratar-se a sericicultura de uma atividade realizada por pequenos produtores desfavorecidos pelas políticas públicas, os quais estão submetidos à disparidade na distribuição de recursos para o agronegócio, à agricultura familiar e ao assentamento de novas famílias. Assim, discorre-se sobre o primeiro domínio acima mencionado.

\section{Do processo técnico de produção}

A sericicultura é uma atividade que, por se pautar na dinâmica do mercado internacional, sofre variações das quais os trabalhadores ficam à mercê. A gestão integrada marca a relação entre os entrevistados com a única empresa atuante no País (BRATAC, 2013), em uma relação desigual entre as partes e sem a existência de contrato formal assinado (PINTO; MUROFUSE; CARVALHO, 2015). Constatouse que o processo de trabalho é manual e envolve todos os membros da família. A atividade se inicia com o plantio das amoreiras e as mudas são fornecidas pela empresa. A primeira atividade é o preparo do solo, para receber as mudas; a terra é revolvida, descompactada, por meio de capina manual ou trator, utilizando a mão de obra feminina e infantil da família.

No processo de crescimento das plantas, há o controle de ervas daninhas, podas e cuidados com o solo, que exigem bastante esforço físico. Também há o risco de acidentes com animais peçonhentos. No período de 2009 a 2013, foram registrados, no Sistema de Informação de Agravos de Notificação, 4.380 casos de acidentes com serpentes no Paraná. Em média, são registrados 870 casos a cada ano. O município de Arapongas (PR) teve 19 registros nesse período, e o município de Diamante do Sul (PR) apresentou 9 registros.

As podas das amoreiras devem ser frequentes, com o uso de serrinha ou trator. Do grupo entrevistado, duas famílias possuíam trator, as outras o alugavam ou realizavam manualmente o trabalho. Em geral, as atividades de poda, corte e transporte manual dos galhos eram feitas pelos homens, exceto em duas famílias: em uma, as mulheres realizavam todas as atividades; na outra, a mulher ajudava no corte dos galhos. Na família em que o casal trabalhou durante bastante tempo com o corte manual dos galhos da amoreira, ambos foram diagnosticados com bursite no ombro e atribuíram tal doença a tal atividade.

A criação do bicho-da-seda pelos produtores rurais inicia a partir do repasse, pela empresa, das larvas do terceiro ao quinto instar. Cabe aos produtores a criação contínua dessas larvas, até a formação do casulo. Para esta atividade, é necessária uma estrutura mínima - para o armazenamento dos galhos de amoreira, o encasulamento, a colheita e seleção dos casulos -, composta por um barracão de alvenaria ou de madeira, denominado sirgaria. Os produtores entrevistados trabalhavam, em média, com duas ou três caixas de lagartas por criada, a partir da entrega, pela empresa, das larvas com cerca de dez dias de vida. As larvas eram acondicionadas nas sirgarias, espalhadas em 
camas, onde eram alimentadas e cuidadas. Essas camas utilizadas pela maioria das famílias entrevistadas situavam-se no chão, e, entre as oito famílias das propriedades visitadas, apenas uma possuía cama suspensa. Se, por um lado, a tecnologia das camas suspensas melhorava as condições de trabalho, por evitar que o trabalhador ficasse 'arcado' durante as tarefas de alimentação, aquelas localizadas no chão facilitavam o manejo durante a limpeza.

Para a alimentação das larvas, os galhos da amoreira eram cortados, diariamente, no início da manhã e no final da tarde, mesmo em dias chuvosos. Os tratos de alimentação para o bicho-da-seda variavam, no terceiro e no quarto instar, entre três e quatro vezes por dia. Porém, no quinto instar, essa frequência aumentava para a distribuição dos galhos a cada duas horas. Em geral, a jornada de trabalho iniciava entre 5 h30min e $6 \mathrm{~h}$, e ia até às $19 \mathrm{~h}$, sendo que, nos períodos de pico da produção, o trabalho se estendia até às $22 \mathrm{~h}$ e, nesse período, o ritmo de trabalho impedia até mesmo a saída de casa, conforme foi relatado pelos entrevistados.

O tempo médio gasto para o corte dos galhos era de aproximadamente duas horas, tarefa esta realizada pelos homens, exceto em duas propriedades. Das sete famílias que trabalhavam com a criação do bicho-da-seda, três não possuíam trator e, portanto, o trabalho era feito de forma manual. A utilização de maquinário para o transporte dos galhos foi apontada como um benefício pelos entrevistados que tinham trator. Observouse que, ao longo do dia, os produtores realizavam várias atividades paralelas, porque a sericicultura não era a única atividade produtiva da propriedade, já que somente essa atividade não lhes possibilitava o sustento, e isso lhes causava sobrecarga de trabalho.

Os entrevistados, além do corte dos galhos da amoreira e da distribuição das folhas na sirgaria, realizavam a limpeza, tanto das sirgarias quanto das camas. Antes da recepção das larvas, era necessária a limpeza da sirgaria, a desinfecção com hidróxido de cal (cal) virgem em pó ou diluída em água e, depois disso, durante a criação, era feito o controle de insetos com inseticidas para prevenir a morte e possibilitar o pleno desenvolvimento das larvas. Para evitar o processo de fermentação, utilizava-se cal sobre as camas, realizava-se a retirada dos restos de folhas e lagartas mortas e as fezes dos bichos. Durante a criação, a desconfortável tarefa de jogar cal nas camas ocorria três vezes ao dia, acompanhada dos constantes cuidados com a umidade, a ventilação e a luminosidade do local. Assim, ficou explícita a preocupação constante com o controle da saúde das lagartas, no entanto, sem que se tivesse o mesmo cuidado com possíveis processos agressivos à saúde humana, pois houve relatos de entrevistados sobre irritação e ardência nos olhos durante o uso da cal. A exposição a cal pode causar irritação nos olhos, pele e sistema respiratório, queimaduras na pele, tosse, bronquite e pneumonite (CENTERS FOR DISEASE CONTROL AND PREVENTION, 2014).

Os relatos dos entrevistados revelaram que, além de desinfetarem a sirgaria com inseticidas, também os utilizavam para o controle de formigas. Em geral, os produtos formicidas apresentam, em sua composição, os agrotóxicos sulfluramida ou fipronil. Vale ressaltar que documento sobre os impactos da sulfluramida e do sulfonato de perfluoroctano (PFOS) sobre a saúde humana e ambiental indica evidências de risco à saúde humana e ambiental (PORTO; MILANEZ, 2009).

Retomando a fase da criação do bicho-da-seda, constatou-se o manejo do processo de emboscamento, iniciado por volta do sétimo dia do quinto instar, que é quando as lagartas estão maduras, deixam de se alimentar e começam a expelir as linhas e formar os casulos. Quando as larvas atingiam a fase de emboscamento, os produtores armavam cartelas, em geral, de papelão, chamadas bosques, distribuindo cerca de 25 bosques por cama. Quando os bosques estavam cheios, o seu peso variava entre 20 
$\mathrm{kg}$ e $30 \mathrm{~kg}$, e, durante esse período, de mais ou menos sete dias, os entrevistados levantavam e baixavam os bosques três vezes por dia. Foi relatado tratar-se de uma das tarefas mais pesadas, por ser manual. Duas sirgarias estavam em fase de instalação de um sistema mecânico para levantar e abaixar os bosques, o que facilitaria a sua suspensão.

Depois de formados, os casulos eram retirados das cartelas e classificados. Segundo os entrevistados, a tarefa era monótona e demandava de três a quatro dias. Os casulos eram classificados em dois grupos: os pequenos, que apresentavam manchas; e os 'graúdos', brancos. Depois de classificados, os casulos passavam por uma máquina de limpeza, denominada 'peladeira', a qual retirava deles uma lã, que também era vendida à empresa. Prontos os casulos para a venda, eram ensacados e enviados à empresa.

Entregues os casulos, a sirgaria e as cartelas tinham que ser limpas, desinfetadas e organizadas. Os rejeitos e bichos-da-seda mortos eram enterrados. Mas o processo de limpeza e desinfecção das cartelas também era feito entre uma ou duas criadas. Para a limpeza dos resíduos de seda, as famílias 'sapecavam' as cartelas com a utilização de um lança-chamas. Nessa tarefa, os entrevistados identificaram dois problemas: a formação de fumaça tóxica, pois as cartelas eram esterilizadas com formol; e a ocorrência de acidentes. Houve relato da ocorrência de incêndio em três propriedades. Depois de fazer o emboscamento de todos os bichos, realizavam a limpeza das camas. Durante esse processo um entrevistado referiu o cheiro forte das folhas podres. Para a limpeza da sirgaria, utilizava-se vassoura, que implica na dispersão dos resíduos no ar.

Para a desinfecção das cartelas todos os entrevistados referiram o uso de formol, sendo que apenas dois utilizavam máscara e luva para manipular o produto. $\mathrm{O}$ formol é carcinogênico para humanos e animais, classificado como Grupo 1 (WORLD HEALTH ORGANIZATION, 2006). A legislação brasileira permite sua exposição ocupacional de
1,6 ppm por período de até $48 \mathrm{~h} /$ semana (BRASIL, 2014). No entanto, segundo o Instituto Nacional do Câncer (2013), não há nível seguro de exposição à substância.

Cabe destacar que, antes do uso da cal, a desinfecção das sirgarias era feita com formol, e os trabalhadores tiveram contato com este último por um período que variou entre 4 e 12 anos. Há aproximadamente três anos, o produto foi substituído pela cal, mas ainda permanecia o uso do formol na desinfecção das cartelas. Nenhum entrevistado soube dizer quais eram os efeitos, na saúde, do contato com o formol. Todavia, foram referidas queixas durante o período que utilizaram formol na desinfecção da sirgaria. Houve relato, de uma das mulheres, que o filho apresentava manchas vermelhas pelo corpo e o marido sentia falta de ar. Também houve relato de faringite alérgica. Embora a exposição ao formol acarrete irritação nos olhos, nariz, garganta, e asma ocupacional (BRASIL, 2001), e seja carcinogênico, os estudos na área da saúde do trabalhador indicam que há carência de dados sobre esse tipo de adoecimento no Brasil, situação que dificulta o planejamento e a organização de ações pelos serviços de saúde.

No que se refere aos direitos do trabalhador, destaca-se, na legislação brasileira, a Norma Regulamentadora 31, que diz respeito à segurança e à saúde no trabalho na agricultura, pecuária, silvicultura, exploração florestal e aquicultura, a qual estabelece os parâmetros para o controle da saúde dos trabalhadores. Entretanto, ela é restrita aos trabalhadores com vínculo empregatício. Esta legislação não contempla os sericicultores, os quais não são considerados empregados da empresa. Além disso, registre-se que há discussão sobre o vínculo empregatício dos sistemas de integração, no Ministério Público Federal do Trabalho, em relação à avicultura e à cultura do tabaco.

Os aspectos envolvidos no processo de trabalho na sericicultura podem ser visualizados no quadro 1. 
Quadro 1. Síntese das atividades, tarefas, cargas, queixas e agravos referidos

\begin{tabular}{|c|c|c|c|}
\hline Atividade & Tarefas identificadas & Cargas & $\begin{array}{l}\text { Queixas, agravos à } \\
\text { saúde referidos }\end{array}$ \\
\hline Cultivo da amoreira. & $\begin{array}{l}\text { Preparo do solo: descompactação } \\
\text { através de capina manual ou } \\
\text { trator, adubação; } \\
\text { Preparo das mudas: corte dos } \\
\text { galhos; } \\
\text { Plantio das mudas: marcação dos } \\
\text { espaços e plantio; } \\
\text { Podas: controle do tamanho das } \\
\text { plantas; } \\
\text { Controle de erva daninha, realiza- } \\
\text { do com agrotóxicos ou de forma } \\
\text { manual. }\end{array}$ & $\begin{array}{l}\text { Físicas: umidade, temperatura, } \\
\text { intempéries; } \\
\text { Químicas: adubos químicos, } \\
\text { agrotóxicos; } \\
\text { Orgânicas: bactérias, fungos, } \\
\text { serpentes; } \\
\text { Mecânicas: riscos de acidentes } \\
\text { com equipamentos; } \\
\text { Fisiológicas e Psíquicas: esforço } \\
\text { físico. }\end{array}$ & $\begin{array}{l}\text { Cansaço físico; } \\
\text { Dores nas costas. }\end{array}$ \\
\hline $\begin{array}{l}\text { Limpeza e desinfec- } \\
\text { ção da sirgaria. }\end{array}$ & $\begin{array}{l}\text { Limpeza das paredes com cal e } \\
\text { água; } \\
\text { Limpeza das camas; } \\
\text { Controle de formigas. }\end{array}$ & $\begin{array}{l}\text { Físicas: umidade; } \\
\text { Químicas: cal, formicidas; } \\
\text { Orgânicas: bactérias, fungos; } \\
\text { Fisiológicas e Psíquicas: esforço } \\
\text { físico. }\end{array}$ & $\begin{array}{l}\text { Irritação e ardência nos } \\
\text { olhos; } \\
\text { Mau cheiro dos resídu- } \\
\text { os das camas; } \\
\text { Cansaço físico; } \\
\text { Dores nas costas; } \\
\text { Laringite crônica. }\end{array}$ \\
\hline $\begin{array}{l}\text { Organização das } \\
\text { camas e disposição } \\
\text { das larvas. }\end{array}$ & $\begin{array}{l}\text { Cobertura das camas suspensas } \\
\text { com lona; } \\
\text { Distribuição das lagartas. }\end{array}$ & $\begin{array}{l}\text { Fisiológicas e Psíquicas: esforço } \\
\text { físico. }\end{array}$ & \\
\hline $\begin{array}{l}\text { Alimentação e } \\
\text { cuidados com as } \\
\text { lagartas. }\end{array}$ & $\begin{array}{l}\text { Corte dos galhos de amoreira, em } \\
\text { qualquer clima; } \\
\text { Distribuição dos galhos nas ca- } \\
\text { mas; } \\
\text { Pulverização das camas com cal } \\
\text { (em pó ou dissolvida em água); } \\
\text { Retirada de lagartas mortas; } \\
\text { Controle de insetos. }\end{array}$ & $\begin{array}{l}\text { Físicas: umidade, temperatura, } \\
\text { intempéries; } \\
\text { Químicas: cal, agrotóxicos; } \\
\text { Orgânicas: bactérias, fungos, } \\
\text { serpentes; } \\
\text { Mecânicas: riscos de acidentes } \\
\text { com equipamentos; } \\
\text { Fisiológicas e Psíquicas: esforço } \\
\text { físico, jornadas prolongadas de } \\
\text { trabalho. }\end{array}$ & $\begin{array}{l}\text { Irritação e ardência nos } \\
\text { olhos; } \\
\text { Cansaço; } \\
\text { Diminuição das horas } \\
\text { de sono; } \\
\text { Pressão relativa à reali- } \\
\text { zação da tarefa. }\end{array}$ \\
\hline $\begin{array}{l}\text { Manejo do proces- } \\
\text { so de embosca- } \\
\text { mento. }\end{array}$ & $\begin{array}{l}\text { Preparo das cartelas: queima dos } \\
\text { resíduos de casulo e esterilização } \\
\text { com formol; } \\
\text { Colocação dos bosques; } \\
\text { Suspensão dos bosques; } \\
\text { Cuidados no processo de embos- } \\
\text { camento. }\end{array}$ & $\begin{array}{l}\text { Químicas: formol, fumaça da } \\
\text { queima de cartelas; } \\
\text { Orgânicas: bactérias, fungos; } \\
\text { Mecânicas: riscos de acidentes } \\
\text { com equipamentos; } \\
\text { Fisiológicas e Psíquicas: esforço } \\
\text { físico, jornadas prolongadas de } \\
\text { trabalho. }\end{array}$ & $\begin{array}{l}\text { Falta de ar; } \\
\text { Problemas de pele; } \\
\text { Dores no corpo; } \\
\text { Dores nas costas e nas } \\
\text { pernas; } \\
\text { Gastrite; } \\
\text { Acidente com fogo; } \\
\text { Dores no estômago. }\end{array}$ \\
\hline $\begin{array}{l}\text { Limpeza e classifi- } \\
\text { cação dos casulos. }\end{array}$ & $\begin{array}{l}\text { Retirada dos casulos dos bosques; } \\
\text { Limpeza dos casulos; } \\
\text { Classificação e entrega dos ca- } \\
\text { sulos. }\end{array}$ & $\begin{array}{l}\text { Fisiológicas e Psíquicas: esforço } \\
\text { físico, jornadas prolongadas de } \\
\text { trabalho. }\end{array}$ & Trabalho repetitivo. \\
\hline $\begin{array}{l}\text { Relação com a } \\
\text { empresa. }\end{array}$ & $\begin{array}{l}\text { Supervisão da produção pelos } \\
\text { técnicos da empresa; } \\
\text { Negociação de financiamento, } \\
\text { dívidas. }\end{array}$ & $\begin{array}{l}\text { Fisiológicas e Psíquicas: pressão } \\
\text { relativa à qualidade dos casulos, } \\
\text { frustração. }\end{array}$ & Estresse. \\
\hline
\end{tabular}

Fonte: Elaboração própria. 
No quadro 1, destaca-se o fato de que as atividades da sericicultura envolvem diversos tipos de carga de trabalho (químicas, orgânicas, mecânicas, fisiológicas, psíquicas e orgânicas). Segundo Laurell e Noriega (1989, P. 110), a identificação destes tipos de carga

[...] possibilita uma análise do processo de trabalho, que extrai e sintetiza os elementos que determinam de modo importante o nexo biopsíquico da coletividade operária.

Já, Breilh (2006) afirma que a vida e a saúde dos trabalhadores vão se moldando, e se desenvolvem tanto no âmbito do trabalho quanto em outros - do consumo, da esfera familiar e da cotidianidade.

\section{Aspectos da vida de consumo e cotidianidade}

As famílias pesquisadas dependiam do rendimento da criação de bicho-da-seda. Ainda que essa criação se constitua em uma fonte de renda, "ela não se desenvolve o ano todo, e se realiza apenas durante os meses compreendidos entre setembro e maio" (PINTO; MUROFUSE, CARVALHO, 2015, P. 241). Dessa forma, as famílias desenvolviam outras atividades para complementarem a renda, conforme já mencionado. Chamou a atenção o fato de apenas um dos entrevistados entregar banana para a merenda escolar, através do Programa Nacional de Alimentação Escolar (PNAE), o que evidencia a dificuldade de acesso às políticas para a agricultura e seus programas, e o endividamento de produtores.

A sericicultura é uma atividade estimulada pelo

estado do Paraná e municípios produtores na perspectiva da criação de postos de trabalho, por meio de incentivos financeiros, linhas de crédito e apoio de infraestrutura. (PINTO; MUROFUSE; CARVALHO, 2015, P. 241).

Todas as famílias entrevistadas tinham dívidas com a empresa detentora das matrizes do bicho-da-seda, e uma família tinha dívida com um banco, por outra linha de financiamento. A relação de produção do sistema integrado impõe uma situação de endividamento para muitos sericicultores, que têm os custos descontados na contraentrega dos casulos e estão subordinados aos critérios estabelecidos pela empresa para os preços dos insumos, produtos e valores financiados para a construção de barracões, entre outros. (PINTO; MUROFUSE; CARVALHO, 2015).

As principais dificuldades (e descontentamentos) relatadas pelos produtores, quanto ao sistema de integração, foram: atingir a classificação estabelecida, pela empresa, do parâmetro do 'casulo perfeito', que recebe maior preço; e o preço dos insumos ser maior do que o do mercado. Também, uma das entrevistadas relatou dificuldade de negociação da dívida, por ser mulher, evidenciando a existência de diferenciação quanto ao gênero. Ao lado do processo de controle da produção e da imposição do modo de produzir da empresa, foram citados os seguintes aspectos positivos, na relação dos produtores com a empresa: o pagamento, feito imediatamente após a entrega do casulo; e a boa relação com os técnicos da empresa, que auxiliam na melhoria da atividade.

Enquanto o grupo dos assentados Arapongas (PR) - possuía o titulo de domínio da terra, os produtores de Diamante do Sul (PR) eram proprietários. A definição das linhas de produção era discutida coletivamente entre produtores do assentamento, e de forma individualizada pelos sericicultores de Diamante do Sul (PR). Afora o fato de serem proprietários da terra, os sericicultores de Diamante do Sul (PR) não apresentaram outras diferenças em relação ao outro grupo. Quanto às condições de habitação, os dois grupos possuíam moradia de alvenaria e/ou mista, com banheiro, água encanada e luz elétrica.

Os pequenos produtores rurais apresentavam uma condição econômica sofrível, considerando que a maioria deles estava 
cadastrada no Programa Bolsa Família. Este programa do governo federal atende famílias com renda per capita inferior a $\mathrm{R} \$ 77,00 / \mathrm{mês}$ e se pauta na garantia de renda, acesso aos serviços públicos e inclusão em atividade de trabalho (BRASIL, 2014).

Em relação à saúde das famílias, inicialmente foi informado, pelos entrevistados, que os familiares não apresentavam agravos, doenças, porém, durante as entrevistas, houve citação de dores nas costas, braços e pernas, fadiga, bursite, laringite crônica, psoríase, vermelhidão na pele, irritação e ardência nos olhos, e hanseníase. A menção dos entrevistados sobre as consequências mais visíveis decorrentes do trabalho, relativas à saúde (ou seja, as de natureza física), e o silêncio dos mesmos quanto à nocividade do trabalho, com suas implicações em nível biopsíquico, sintetizadas no quadro 1, revela a dificuldade destes para estabelecerem uma relação entre o trabalho e o processo saúde-doença como expressão da visão hegemônica vigente na nossa sociedade.

Quanto à assistência à saúde, os entrevistados utilizavam o Sistema Único de Saúde (SUS). No assentamento, havia uma unidade de saúde, que atendia uma vez por semana. Porém, um dos entrevistados informou que nem sempre a equipe de saúde conseguia se deslocar de Arapongas (PR) até a unidade, por falta de veículo. Já no município de Diamante do Sul (PR), o acompanhamento da saúde dos entrevistados era feito pela equipe de saúde da família, e foi avaliado como bom.

Em relação à educação, o assentamento de Arapongas (PR) definiu como uma das prioridades a melhoria da escolaridade dos assentados. Não havia nenhum caso de analfabetismo e muitos continuavam estudando. $\mathrm{O}$ ensino fundamental era ministrado em uma escola municipal próxima ao assentamento. Para cursar o ensino médio, os alunos deslocavam-se para o município de Aricanduva (PR). Havia jovens frequentando cursos universitários.
Já o município de Diamante do Sul (PR) contava não só com escolas para o nível fundamental e médio, como também sua população tinha acesso à escola para as crianças, inclusive com transporte. Para cursar o ensino superior, os estudantes deslocavam-se para o município de Cascavel (PR). Em relação aos adultos, tanto no município de Arapongas (PR) quanto em Diamante do Sul (PR), foram indicados, como problemas para a continuidade dos estudos, a dificuldade em relação ao transporte e aos horários de trabalho na sericicultura, além dos afazeres domésticos.

As atividades de lazer referidas pelos entrevistados foram jogos de futebol, bailes e cultos, sendo que algumas famílias informaram que costumavam ficar em casa, assistindo televisão ou fazendo serviços na propriedade.

\section{Aspectos da vida política e ideológica}

O processo histórico de formação do assentamento indica a existência de um encadeamento organizativo vinculado à luta pela terra. Desde o seu início, as linhas de produção do assentamento foram discutidas coletivamente pelo grupo, a partir da orientação geral do Movimento Sem Terra. O relato colhido apontou a dificuldade de articulação entre os assentados, e a falta de estrutura para a implementação da produção de alimentos. Inicialmente, a criação do bicho-da-seda foi uma de suas principais atividades. Atualmente, a prioridade da linha de produção no assentamento é a produção de leite e, assim, os esforços estão concentrados no funcionamento do laticínio inaugurado no ano de 2013. Com a diminuição do número de produtores na criação do bicho-da-seda, houve um enfraquecimento organizativo, até chegar à situação atual, na qual os produtores do assentamento não participam de nenhuma associação de sericicultores nem se reúnem para discutir os problemas comuns. Os entrevistados de Diamante do Sul (PR) participavam da Associação de 
Sericicultores de Diamante do Sul. A cada ano, em média, eram realizadas três ou quatro reuniões. Mesmo com algum tipo de organização dos produtores, tanto do assentamento quanto do município de Diamante do Sul (PR), identificou-se desinformação sobre a cadeia produtiva, políticas públicas e produtos químicos utilizados no processo de trabalho.

Duas instâncias tratam da organização e do desenvolvimento da sericicultura no Paraná: a Federação das Associações de Sericicultores do estado do Paraná, composta por 17 associações de sericicultores; e a Câmara Técnica do Complexo da Seda do estado do Paraná, criada em 2004, composta por órgãos governamentais ligados à agricultura, aos sindicatos, à empresa e a universidades. Analisando-se as atas das reuniões da Câmara Técnica do Complexo da Seda, no período de 2004 a 2013, entre os temas abordados, encontram-se: o problema da contaminação das lagartas por agrotóxicos, devido à pulverização aérea e/ou terrestre; o acompanhamento do mercado da seda; a organização dos encontros estaduais da sericicultura, realizados anualmente; as linhas de crédito para os produtores; e a pesquisa sobre a sericicultura. Outro elemento que foi identificado durante as entrevistas diz respeito às relações de gênero. Embora todas as mulheres trabalhassem na criação do bicho-da-seda, exceto em uma entrevista, na qual o casal prestou informações, em todas as outras houve apenas a participação dos homens. No retorno a uma das propriedades, para a complementação das informações, o entrevistado não estava na residência, e a mulher, a princípio, disse: "Sobre a criação, é ele que sabe", porém, ao longo da conversa, ela deu uma série de informações sobre a atividade. Segundo Carvalho (2012), a questão de gênero perpassa as famílias camponesas, nas quais há sobrecarga de trabalho para a mulher e desvalorização do trabalho feminino.

\section{Aspectos da vida de relação com a natureza}

Todos os entrevistados ressaltaram que a atividade de criação do bicho-da-seda não tem impactos no ambiente pelo fato de não usar agrotóxicos. E, como ponto positivo, dois entrevistados referiram que a plantação de amoreiras evita a erosão. Por outro lado, foi identificado o uso de herbicidas nas amoreiras em, pelo menos, três propriedades. Dois problemas ambientais, que aparecem nas entrevistas e têm repercussão no trabalho e na vida das famílias, dizem respeito à suspeita da contaminação do manancial de abastecimento de água por agrotóxicos do município de Arapongas (PR) e à pulverização aérea desses produtos nas propriedades vizinhas, em ambos os municípios estudados, e em outras culturas.

Os moradores do assentamento de Arapongas (PR), em conjunto com moradores do município de Aricanduva (PR), criaram o Movimento Nacional em Defesa dos Mananciais, em função da suspeita de contaminação da área do manancial que abastece as cidades de Londrina (PR), Apucarana (PR) e Arapongas (PR). A contaminação do solo e da água por agrotóxicos compromete a saúde da população do campo e da cidade, além dos sistemas de produção, como ilustra o fragmento da fala do entrevistado:

A gente sabe que tem propriedade parando de produzir. As empresas não produzem mais frango porque a água não é adequada para criar frango. Outros sitiantes venderam o sítio porque descobriram que a água está contaminada. Então, uma grande preocupação nossa aqui no assentamento é que qualquer linha de produção, no futuro, pode ser que não seja mais viável. A produção do bicho-da-seda, de leite, hortaliças e frutas... Se a água tiver com contaminação que não possa ser usada nessa produção, nessas plantações, tampouco vai servir para beber, tomar banho, fazer comida. [...] de repente, a gente vai ter que ir embora. (Entrevistado). 
Matéria intitulada 'MP retoma a investigação no Ribeirão dos Apertados/MP retoma investigação em Arapongas', publicada no Jornal Folha de Londrina, informa que o problema da contaminação da água no município de Arapongas (PR) foi apresentado pelos moradores de Aricanduva (PR), no final de 2001, a um advogado, que encaminhou a queixa ao Ministério Público. A denúncia citava a desativação de poços semiartesianos por problemas de contaminação (AUGUSTO, 2008).

Segundo os moradores daquela região, a empresa produtora de agrotóxicos está localizada sobre a área do manancial que abastece Arapongas (PR). Além da contaminação da água, eles convivem com o odor de produtos químicos produzido pela indústria, com o ruído das máquinas e com a emissão de um pó branco pelas chaminés. No período noturno, é comum utilizarem toalhas molhadas nas frestas das janelas e portas das casas, para evitar a entrada dos produtos. Segundo os representantes dos moradores, um indicativo da contaminação é que, quando acontece a identificação de um poço contaminado, a empresa realiza a compra da área. Muitas propriedades já foram adquiridas por essa empresa. Há um processo em andamento, no Ministério Público Estadual, para a averiguação das denúncias de contaminação.

Em 2014, a pedido do Ministério Público Estadual, foi analisada a água de consumo humano em Aricanduva (PR). Os resultados indicaram contaminação por agrotóxicos. Porém, a Companhia de Saneamento do Paraná (Sanepar) distribuiu um panfleto, na comunidade, informando que a água não está poluída (COMPANHIA DE SANEAMENTO DO PARANÁ, 2014).

Em relação à morte de lagartas provocada pelo uso de agrotóxicos, em áreas vizinhas às propriedades que criam o bicho-da-seda, tem-se que este problema é recorrente nas atas das reuniões da Câmara Técnica do Complexo da Seda do estado do Paraná. Em 2012, o problema da morte de lagartas por agrotóxicos atingiu 38 produtores, em cinco municípios do estado do Paraná: Colorado, Paranacity, Uniflor, Castelo Branco e Nova Esperança (AGÊNCIA DE DEFESA AGROPECUÁRIA DO PARANÁ, 2013). No Assentamento Dorcelina Folador, em maio de 2014, houve a morte de lagartas de cinco sericicultores, e contaminação de hortaliças e flores devida à pulverização por agrotóxicos em propriedade vizinha. É importante frisar que a morte das lagartas é um indicador ambiental do processo de contaminação, que pode atingir às famílias, tanto por exposição direta quanto pela ingestão de hortaliças e animais envenenados.

\section{Dos processos protetores e destrutivos da saúde dos(as) trabalhadores(as) da sericicultura: elementos para a vigilância da saúde dos trabalhadores}

O foco nos processos que ocorrem na vida de trabalho, na esfera do consumo, no domínio da vida cultural e nas relações ecológicas, nas dimensões do geral, do particular e do singular, possibilita uma intervenção mais abrangente para responder as necessidades desses(as) trabalhadores(as). A matriz de processos críticos é uma ferramenta que permite maior compreensão do perfil epidemiológico dos coletivos de trabalhadores(as).

A construção da matriz se constitui em um processo autônomo dos grupos sociais, na perspectiva de identificar as necessidades coletivas de saúde e monitorá-las ao longo do tempo. Neste estudo, apresentam-se apenas elementos para a construção da matriz dos processos críticos, pois a sua elaboração ocorre na discussão e na análise dos coletivos de trabalhadores. Pela reduzida quantidade de trabalhadores participantes do grupo focal, espaço coletivo criado para a discussão da matriz, não foi possível um maior aprofundamento dessa ferramenta.

A pesquisa demonstrou que os(as) trabalhadores(as) da sericicultura, voltados à criação do bicho-da-seda para a produção 
de casulo, estão submetidos a processos que protegem a saúde e a processos que podem prejudicar a sua saúde e a de suas famílias. Este grupo de trabalhadores da pequena agropecuária familiar encontra-se subordinado a um modelo agrícola hegemonizado pelo capital industrial e financeiro, pautado na monocultura de exportação, na produção de commodities, no uso intensivo de agrotóxicos e fertilizantes, no maquinário agrícola, na biotecnologia e na concentração de terras. O controle, pelo agronegócio, ocorre tanto em relação às políticas agrícolas quanto em relação aos territórios. Desta forma, a pequena agropecuária familiar, quando não é territorializada, é monopolizada por essa dinâmica. Isto porque as pequenas propriedades tornam-se extensões da indústria, e também ficam à mercê de processos externos, que ultrapassam os limites das propriedades - por exemplo, as pulverizações aéreas por agrotóxicos, que causam a morte das lagartas e a contaminação das famílias. Por outro lado, em uma linha de resistência, há um processo de disputa deste modelo, que, com menor poder, se pauta na produção de alimentos e não de commodities. Este processo, embora tenha acesso restrito ao financiamento público, se coloca como uma possibilidade concreta.

Nesse contexto, o modo de vida das famílias pesquisadas se caracteriza pela dificuldade de desenvolvimento de linhas de produção autônomas, pelo acesso difícil ao crédito público, pela falta de assistência técnica pública para outras linhas de produção, pela renda sazonal e pelo desenvolvimento de várias atividades para a composição da renda.

Em relação às políticas públicas, inexistem programas, ações que possibilitem aos/ às trabalhadores(as) a continuidade dos estudos. Existem, ainda, falta de acesso aos bens públicos e culturais, dificuldade de acesso aos serviços especializados de saúde e precariedade das condições de trabalho das equipes de saúde local, para atendimento das necessidades da população. Instala-se, portanto, um quadro de vulnerabilidade para os trabalhadores e suas famílias.

O processo técnico de trabalho impõe a inclusão das famílias em um regime de terceirização sem o pagamento dos direitos trabalhistas, inclusive, com a participação de mulheres, crianças e adolescentes. Desta forma, os produtores ficam desprovidos desses direitos já conquistados pela classe trabalhadora. Há o contato com substâncias químicas tóxicas, esforço físico, jornadas prolongadas de trabalho, situações que causam preocupação e estresse; desinformação sobre acesso às políticas públicas, impacto das condições de trabalho na saúde. Também há dificuldade de articulação e organização dos pequenos produtores, para fazerem frente às negociações com a empresa.

Por outro lado, como processos protetores, todos os produtores são proprietários ou têm título de domínio da terra; algumas famílias possuem equipamentos que melhoram as condições de trabalho; e existe uma linha de produção desenvolvida no assentamento (produção de laticínios). A atividade da sericicultura se apresenta como uma alternativa de renda aos pequenos produtores. A empresa fornece assistência técnica, facilita o acesso ao crédito e procede ao pagamento da produção logo após a entrega.

Por sua vez, a Câmara Técnica do Complexo da Seda do estado do Paraná articula os diversos atores que compõem tal cadeia produtiva, para a resolução de problemas. Há, também, a política interna do Assentamento Dorcelina Folador, que prioriza a educação e linhas de produção sustentáveis; e há acesso aos programas Bolsa Escola, Programa Nacional de Alimentação Escolar e Programa de Aquisição de Alimentos.

No quadro 2, podem-se visualizar os processos protetores e destrutivos identificados no estudo empírico, os quais possibilitam a construção da matriz de processos críticos e fornecem subsídios para as ações de vigilância em saúde do trabalhador. 
Quadro 2. Matriz de Processos Críticos - Trabalhadores(as) da Sericicultura no Paraná

\begin{tabular}{|c|c|c|c|}
\hline Campo & Dimensões & Processos Protetores & Processos Destrutivos \\
\hline Singular & $\begin{array}{l}\text { Consumo e } \\
\text { cotidiano }\end{array}$ & $\begin{array}{l}\text { - Todos são proprietários ou têm título de } \\
\text { domínio da terra; } \\
\text { - Famílias acessam benefício da assistência } \\
\text { social; } \\
\text { - Realizam agricultura de subsistência e } \\
\text { criação de animais; } \\
\text { - Participam do Programa Nacional de } \\
\text { Aquisição de Merenda Escolar (PNAE) e } \\
\text { do Programa de Aquisição de Alimentos } \\
\text { (PAA); } \\
\text { - Algumas famílias possuem trator, cami- } \\
\text { nhonete para transporte de galhos, aciona- } \\
\text { mento mecânico dos bosques; } \\
\text { - Produtores alfabetizados; } \\
\text { - Formas de lazer: futebol, bailes. }\end{array}$ & $\begin{array}{l}\text { - Renda sazonal da sericicultura, com neces- } \\
\text { sidade de complementação via outras ativi- } \\
\text { dades; } \\
\text { - Faltam informaç̃es aos agricultores sobre: a } \\
\text { toxicidade dos produtos químicos que utilizam, } \\
\text { as regras de classificação dos casulos, dívidas } \\
\text { com insumos, direitos (à saúde, entre outros), } \\
\text { quanto a alternativas produtivas; } \\
\text { - Escolas rurais oferecem apenas os níveis } \\
\text { básicos de escolaridade, dificuldade de acesso } \\
\text { de crianças e adultos a outros níveis de ensino; } \\
\text { - Acesso ao serviço de saúde: dificuldade de } \\
\text { acesso à rede especializada, falta de condições } \\
\text { de trabalho para as equipes de saúde; } \\
\text { - Falta de acesso a bens e atividades culturais. }\end{array}$ \\
\hline
\end{tabular}

\section{Considerações finais}

O estudo empírico demonstrou que o modo de vida dos sericicultores está intimamente ligado à dinâmica do capital industrial e financeiro, que interfere diretamente no processo de trabalho e apresenta uma série de contradições indicativas de ações, umas que protegem e outras destrutivas à saúde desse grupo social. Reforça a indicação de processos a serem alterados e/ou monitorados para a proteção da saúde desta população e descarta a ideia da inexistência de nocividade no trabalho da sericicultura.

Com a incursão e a descrição do modo de vida dos(as) trabalhadores(as) da sericicultura, foram evidenciados problemas, como cansaço físico; dores no corpo, diminuição das horas de sono, falta de ar, problemas de pele, gastrite, dores de estômago, estresse, pressão psicológica e laringite. Entre as cargas e os processos de trabalho evidenciados, destacam-se o contato constante com produtos químicos tóxicos, jornadas prolongadas de trabalho, tarefas noturnas, trabalho infantil e adolescente, risco de acidentes com fogo e serpentes, contaminação ambiental por agrotóxicos. Tal conjunto de problemas aponta e reforça a necessidade da interdisciplinaridade para estudo e análise da saúde coletiva. Há necessidade urgente de se tratarem as questões que dizem respeito às políticas públicas, à organização dos trabalhadores e aos centros de pesquisa.

Também é urgente o monitoramento da saúde dos sericicultores e suas famílias, em relação ao uso do formol, produto químico carcinogênico. Este problema requer discussão, pelo coletivo de trabalhadores e órgãos públicos, na perspectiva da eliminação do produto do processo de trabalho, como princípio da precaução. Conclui-se, ainda, que faltam informações aos trabalhadores, sobre cargas, processos de trabalho e efeitos à saúde. Em função disto, cabe aos profissionais da área da saúde do trabalhador desenvolverem estratégias de comunicação de risco. Situações relacionadas a acidentes com serpentes e com fogo precisam ser monitoradas, também, pelas equipes de vigilância em saúde do trabalhador, na perspectiva de prevenção. A vigilância em saúde do trabalhador deve ser informada e capacitada quanto aos processos protetores e destrutivos, para acompanhamento da saúde deste grupo social.

Foram constatadas, também, questões relacionadas ao direito, que aparecem fortemente no processo. $\mathrm{E}$ as questões 
relacionadas à legislação trabalhista e ao direito ambiental, em relação à contaminação por agrotóxicos, precisam ser verificadas. Assim, entre as indicações de novos estudos, há a necessidade de pesquisa sobre o direito trabalhista e ambiental, para subsidiar a luta dos trabalhadores. Há que se debruçar, também de forma detalhada, sobre o trabalho infantil e adolescente no sistema integrado, além de ser necessária a promoção de estudos comparativos sobre o sistema integrado no

\section{Referências}

\author{
AGÊNCIA DE DEFESA AGROPECUÁRIA DO \\ PARANÁ. Defesa Agropecuária em ação. Boletim \\ Informativo da ADAPAR, Curitiba, n. 6, abr./maio, \\ 2013. Disponível em: <http://www.adapar.pr.gov.br/ \\ arquivos/File/ATG/BoletimAbril2013.pdf > . Acesso em: \\ 4 fev. 2014
}

AUGUSTO, L. MP retoma investigação em Arapongas. Folha de Londrina, Londrina, 9 dez. 2008. Disponível em: <http://www.folhadelondrina.com.br/cidades/ mp-retoma-investigacao-em-arapongas-665247.html>. Acesso em: 10 nov. 2014.

BRANCALHÃO, R. M. C.; TORQUATO, E. F. B.; CASTRO, M. E. B. Identificação de um isolado de Bombyx mori multiple nucleopolyhedrovirus (BMMNPV) no estado do Paraná, Brasil. Brasília, DF: Embrapa Recursos Genéticos e Biotecnologia, 2002. Disponível em: $<$ https://www.infoteca.cnptia.embrapa. br/bitstream/doc/175287/1/bp033.pdf>. Acesso em: 5 nov. 2014.

BRASIL. Doenças relacionadas ao trabalho: manual fumo, na avicultura e na sericicultura.

\section{Colaboradores}

Pinto, N. F. e Murofuse, N. T. participaram da concepção, do delineamento do estudo, da análise e interpretação dos resultados, da redação e revisão crítica do conteúdo intelectual do manuscrito e da aprovação da versão final. de procedimentos para os serviços de saúde. Brasília, DF: Ministério da Saúde, 2001. Disponível em: <http:// dtr2004.saude.gov.br/susdeaz/instrumento/arquivo/16_Doencas_Trabalho.pdf >. Acesso em: 5 nov. 2014.

Ministério do Desenvolvimento Social e Agrário. Bolsa família. Brasília, DF: MDS, 2014. Disponível em: <http://www.mds.gov.br/bolsafamilia>. Acesso em: 9 jun. 2014.

INSTITUTO NACIONAL DO CÂNCER (INCA). Formol ou formaldeído: fatores de risco. Rio de Janeiro: INCA, 2013. Disponível em: <http://www.inca.gov.br/ conteudo_view.asp?id=795>. Acesso em: 15 jul. 2013.

BRASIL. Ministério do Trabalho. Normas Regulamentadoras. Brasília, DF: MT, 2014. Disponível em: <http://portal.mte.gov.br/data/files/8A7C816A429 5EFDF0143067D95BD746A/NR-31\%20(atualizada\%20 2013).pdf>. Acesso em: 9 jan. 2014.

BRATAC FIAÇÃO DE SEDA (BRATAC). Institucional. 2013. Disponível em: <http://www.bratac.com.br/ 
bratac/pt/index.php?GTR_VARS_acesso=modulos/ conteudo/detTexto.php\&GTR_VARS_codtexto=1\&>. Acesso em: 4 maio 2013.

BREILH, J. Epidemiologia crítica: ciência emancipadora e interculturalidade. Rio de Janeiro: Fiocruz, 2006.

La epidemiología crítica: una nueva for-

ma de mirar la salud en el espacio urbano. Salud Colectiva, Buenos Aires, v. 6, n. 1, p. 83-101, jan./ abr., 2010. Disponível em: <http://www.scielo.org.ar/scielo.php?script=sci_arttext\&pid $=$ S1851-82652010000100007 $>$. Acesso em: 4 maio 2013.

CARVALHO, L. N. Diálogo de saberes no encontro de culturas. 2012. Trabalho apresentado como requisito parcial para aprovação na Disciplina Diálogo de Saberes no Encontro de Culturas, Curso Técnico em Agroecologia, São Miguel do Iguaçu, PR, 2012. Mimeografado.

\section{CENTERS FOR DIASEASE CONTROL AND}

PREVENTION. Niosh Pocket Guide to Chemical Hazards Calcium hydroxide. 2014. Disponível em: <http://www.cdc.gov/niosh/npg/npgd0092.html>. Acesso em: 10 dez. 2014.

LAURELL, A. C.; NORIEGA, E. M. Processo de produção e saúde: trabalho e desgaste operário. São Paulo: HUCITEC, 1989.

MINAYO, M. C. S. Pesquisa social: teoria, método e criatividade. 21. ed. Rio de Janeiro: Vozes, 2002.

OJEDA, I. Reforma agrária perde fôlego na agenda nacional. Desafios do Desenvolvimento, Brasília, DF, v. 9, n. 75, p. 40-48, 2012. Disponível em: <http://www.ipea. gov.br/desafios/images/stories/PDFs/desafios075_ completa.pdf>. Acesso em: 27 nov. 2014.

\section{COMPANHIA DE SANEAMENTO DO PARANÁ.}

Sanepar informa: aos moradores de Aricanduva. Paraná: Companhia de Saneamento do Paraná, 2014. Mimeografado.
PINTO, N. F.; MUROFUSE, N. T. M.; CARVALHO, M. Processos e cargas de trabalho e as saúde dos trabalhadores na sericicultura: uma revisão. Rev. Bras. Saúde Ocup., São Paulo, v. 40, n. 132, p. 237-247, 2015.

PORTO, M. F.; MILANEZ, B. Documento Técnico sobre os impactos da sulfluramida e do sulfonato de perfluoroctano (PFOS) sobre a saúde humana e ambiental. Rio de Janeiro: Fiocruz, 2009. Disponível em: <http:// www2.camara.leg.br/atividade-legislativa/comissoes/ comissoes-permanentes/capadr/audiencias-publicas/ audiencias-2009/rap140409zuleica.pdf>. Acesso em: 13 dez. 2014.

TAKAHASHI, R.; TAKAHASHI, K. M.; TAKAHASHI, L. S. Sericicultura: uma promissora exploração agropecuária. 2. ed. Jaboticabal: Funep, 2009.

VIJAYABHASKARARAO, A. et al. An epidemiological and environmental survey on occupational health hazards during silk production and processing. India: Pondicherry University, 2013. Disponível em: <http:// elsevier.conference-services.net/resources/247/3306/ pdf/ENVR2013_0709.pdf>. Acesso em: 13 dez. 2014.

WANI, K. A.; JAISWAL, Y. K. Health hazards of rearing silk worms and environmental impact assessment of rearing households of Kashmir, India. Nature Environment and Pollution Technology, India, v. 10, n. 1, mar. 2011. Disponível em: <http://www.neptjournal. com/upload-images/NL-21-17-(17)-B-163.pdf >. Acesso em: 13 dez. 2014.

\section{WORLD HEALTH ORGANIZATION.}

INTERNATIONAL AGENCY FOR RESEARCH ON

CANCER. IARC Monographs on the Evaluation of Carcinogenic Risks to Humans. Lyon, France: IARC, 2006. v. 88.

Recebido para publicação em agosto de 2016

Versão final em janeiro de 2017

Conflito de interesses: inexistente

Suporte financeiro: não houve 